\title{
Crescimento Inicial e Absorção de nutrientes pelo Algodoeiro Cultivado sobre A PAlHAdA DE Brachiaria ruziziensis ${ }^{1}$
}

\author{
Initial Growth and Nutrient Absorption of Cotton Cultivated on Congo Grass Residues \\ ECHER, F.R. ${ }^{2}$, CASTRO, G.S.A. ${ }^{2}$, BOGIANI, J.C. ${ }^{3}$ e ROSOLEM, C.A. ${ }^{4}$
}

\begin{abstract}
RESUMO - As gramíneas forrageiras possuem alta capacidade para produzir palha no sistema de semeadura direta em integração lavoura-pecuária. No entanto, essas plantas podem reduzir o crescimento das culturas, em função de efeitos alelopáticos ou pela competição por nutrientes. O objetivo deste trabalho foi avaliar o efeito de resíduos culturais de Brachiaria ruziziensis no crescimento inicial e no acúmulo de nutrientes na parte aérea do algodoeiro, quando foram deixados sobre o solo ou no solo. O experimento foi conduzido em casa de vegetação, sendo o algodão cultivado com os tratamentos: raízes e parte aérea da braquiária cultivada previamente e deixadas no vaso; parte aérea da braquiária colocada sobre o solo; raízes da braquiária ficaram no solo, mas a parte aérea foi retirada; uma testemunha (sem braquiária). As raízes de braquiária remanescentes no solo causaram diminuição na produção de matéria seca da parte aérea e no crescimento inicial das raizes do algodoeiro. O teor e o acúmulo de $\mathrm{N}$ na parte aérea da planta foram menores na presença de raízes de braquiária, porém o teor de $\mathrm{P}$ na parte aérea do algodoeiro foi maior, e tanto o teor como o acúmulo de $\mathrm{K}$ na parte aérea do algodão foram maiores quando este foi cultivado sobre resíduos da parte aérea da braquiária.
\end{abstract}

Palavras-chave: Gossypium hirsutum, crescimento radicular, rizotron, sistema plantio direto, palhada.

\begin{abstract}
Grasses have a high ability to produce straw under no-tillage system. However, these plants can reduce the growth of crops, caused by allelopathic effects or competition for nutrients. An experiment was conducted to study the early growth and nutrition of cotton as affected by residues of Congo grass (Brachiaria ruziziensis) cropped before in the same pots. Cotton was grown in glass-windowed pots with a combination of congo grass roots, with shoot residues being left or not. Cotton growth and $N$ accumulation were decreased in the presence of congo grass roots in the soil, probably due to $N$ immobilization. However, these plants accumulated more $P$. When residues of congo grass shoots were left on the soil surface, cotton $K$ uptake was increased.
\end{abstract}

Keywords: Gossypium hirsutum, root growth, rhizotron, no-till system, straw residues.

\section{INTRODUÇÃO}

O uso de culturas anuais em reforma de pastagens degradadas vem se intensificando nas principais regiões produtoras de grãos no Brasil. No entanto, há indícios de redução de crescimento, amarelecimento e diminuição na produção das culturas, em decorrência da decomposição da palhada das pastagens no solo (Maciel et al., 2003). Esse fato pode estar ligado a efeitos alelopáticos, definidos como o efeito inibitório ou benéfico, direto ou indireto, de uma planta sobre outra ou pela competição por nutrientes, especialmente o nitrogênio (Souza et al., 2006). Souza Filho \& Mourão Jr. (2010) observaram efeitos alelopáticos

Recebido para publicação em 4.7.2011 e aprovado em 9.6.2012.

2 Engo-Agro-, Doutorando em Agronomia, Universidade Estadual Paulista, FCA/Unesp, Botucatu-SP, <fabioecher@gmail.com>, <gsacastro@hotmail.com>. ${ }^{3}$ Eng--Agr $^{\circ}$., D.Sc., Pesquisador da Empresa Brasileira de Pesquisa Agropecuária, Embrapa Algodão, <julio@cnpa.embrapa.br>. ${ }^{4}$ Engo-Agr ${ }^{\circ}$., D.Sc., Professor Titular da FCA/Unesp, Botucatu, <rosolem@fca.unesp.br>. 
diferenciados de folhas e raízes de espécies do gênero Brachiaria sobre plantas daninhas.

Além disso, a utilização de forrageiras tropicais para produção de palha sob sistema de integração lavoura-pecuária (ILP) difundiu-se em regiões de inverno seco (Kluthcouski \& Aidar, 2003). Entre as espécies de cobertura utilizadas nos sistemas de produção em que está inserido o algodoeiro, destacam-se forrageiras do gênero Brachiaria, especialmente $B$. ruziziensis. Essa espécie tem sido utilizada devido à alta produção de matéria seca em curto espaço de tempo e à sua adaptação a vários tipos de clima e solo, preferencialmente com boa drenagem, tolerando fertilidade média do solo.

Essa espécie apresenta boa proteção contra a erosão, além de boa habilidade para competir com plantas invasoras (Hirata et al., 2009). A utilização dessas plantas proporciona melhoria nas propriedades físicas do solo, assim como outros beneficios, como o aumento da atividade da micro e macrofauna, além de a cobertura do solo diminuir a temperatura em até $10^{\circ} \mathrm{C}$ (Cook et al., 2006; Prando et al., 2010). Recentemente, foi levantada a possibilidade de $B$. ruziziensis modificar a dinâmica do $\mathrm{P}$ no solo, tornando-o mais disponivel à cultura subsequente (Merlin et al., 2009).

O cultivo de espécies de cobertura com alta relação $\mathrm{C} / \mathrm{N}$, tanto da parte aérea quanto das raízes, como é o caso das gramíneas forrageiras tropicais, pode alterar o desenvolvimento inicial das culturas subsequentes (Souza et al., 2006), devido também à imobilização temporária de $\mathrm{N}$ pela biomassa microbiana do solo (Perin et al., 2006) e pela competição por outros nutrientes. Olibone et al. (2006) observaram que a soja cultivada sobre a palha de sorgo-guiné apresentou menor crescimento da parte aérea e da raiz, resultando em menor acúmulo de nutrientes na parte aérea. Por outro lado, a ciclagem e a liberação de $\mathrm{N}$ da biomassa microbiana são mais rápidas do que outras frações da matéria orgânica do solo, pois, conforme os microrganismos morrem, eles são rapidamente mineralizados por outros, liberando os nutrientes imobilizados, ocorrendo a remineralização (Mary et al., 1996). A liberação de nutrientes da palha, especialmente de $\mathrm{K}$, pode representar um aporte significativo dele para a cultura subsequente
(Foloni \& Rosolem, 2004; Calonego et al., 2005; Rosolem et al., 2006).

Assim, embora a cobertura do solo tenha inúmeros efeitos positivos, podendo facilitar a emergência e o desenvolvimento inicial das culturas (Silva \& Rosolem, 2001), efeitos alelopáticos ou mesmo a competição pelo nitrogênio disponivel no solo podem afetá-lo negativamente (Souza et al., 2006). Como o uso da braquiária vem se intensificando como planta de cobertura ou como forrageira na integração lavoura-pecuária, inclusive em rotação com o algodoeiro, o objetivo deste trabalho foi avaliar o efeito de residuos culturais de B. ruziziensis no crescimento inicial e no acúmulo de nutrientes na parte aérea do algodoeiro, quando foram deixados sobre o solo ou no solo.

\section{MATERIAL E MÉTODOS}

O experimento foi conduzido em casa de vegetação, em Botucatu-SP. O solo utilizado, classificado como Latossolo Vermelho Distroférrico (Embrapa, 1999) de textura média (630 $\mathrm{g} \mathrm{kg}^{-1}$ de areia, $40 \mathrm{~g} \mathrm{~kg}^{-1}$ de silte e $330 \mathrm{~g} \mathrm{~kg}^{-1}$ de argila), foi seco ao ar e peneirado em malha de $4 \mathrm{~mm}$. A análise química (Raij et al., 2001) revelou os seguintes valores: $\mathrm{pH}$ $\left(\mathrm{CaCl}_{2}\right) 4,1 ; 1,0 \mathrm{mg} \mathrm{dm}^{-3}$ de $\mathrm{P}_{\text {resina }} ; 18,0 \mathrm{~g} \mathrm{dm}^{3} \mathrm{de}$ matéria orgânica; 75,0 mmol $_{c} \mathrm{dm}^{-3} \mathrm{de} \mathrm{H}+\mathrm{Al}$; 0,1 $\mathrm{mmol}_{\mathrm{c}} \mathrm{dm}^{-3}$ de $\mathrm{K} ; 4,0 \mathrm{mmol}_{\mathrm{c}} \mathrm{dm}^{-3}$ de $\mathrm{Ca}$; 1,0 $\mathrm{mmol}_{\mathrm{c}} \mathrm{dm}^{-3} \mathrm{de} \mathrm{Mg} ; 5,1 \mathrm{mmol}_{\mathrm{c}} \mathrm{dm}^{-3}$ de SB; $81,1 \mathrm{mmol}_{\mathrm{c}} \mathrm{dm}^{-3}$ de CTC; e 6,3\% de saturação por bases (V). Foi aplicado calcário dolomítico (CaO: 28\%, MgO: 20\% e PRNT: 95\%) em quantidade calculada para elevar a saturação por bases a $70 \%$. O solo foi umedecido e incubado sob lona plástica por 30 dias. Em seguida, foi seco ao ar e adubado com $50 \mathrm{mg} \mathrm{dm}^{-3}$ de N (ureia) $150 \mathrm{mg} \mathrm{dm}^{-3}$ de $\mathrm{P}$ (superfosfato simples) e $150 \mathrm{mg} \mathrm{dm}^{-3}$ de $\mathrm{K}$ (cloreto de potássio).

Os tratamentos constituiram-se do cultivo de algodão na presença ou não de restos vegetais de Brachiaria ruziziensis no solo e/ou sobre o solo, como segue: 1 - planta inteira (com raiz e com parte aérea da forrageira); 2 - somente raiz; 3 - somente parte aérea (proveniente do tratamento 2); e 4 - testemunha (sem restos de raiz ou parte aérea). Os tratamentos que não continham parte aérea de braquiária tiveram a superfície do solo coberta com 
material inerte (flocos de espuma cinza-clara), para simular os efeitos da palha, como a diminuição da perda de água por evaporação e da temperatura do solo.

As unidades experimentais constituíramse de tubos de PVC com diâmetro de $0,26 \mathrm{~m} \mathrm{e}$ altura de 0,60 m. Os tubos foram cortados ao meio no sentido longitudinal, formando uma face plana, na qual se instalou uma parede de vidro (rizotron) para propiciar o acompanhamento visual do crescimento radicular das culturas. Sobre a parede de vidro havia uma tampa deslizante de madeira laminada, para evitar a incidência de luz, que inibiria o crescimento radicular. Os tubos foram inclinados a $15^{\circ}$, para possibilitar o crescimento do sistema radicular paralelamente ao vidro. O volume de terra contido em cada unidade experimental foi de $16 \mathrm{dm}^{3}$. O teor de água foi monitorado diariamente e corrigido sempre que necessário, para que permanecesse próximo à capacidade de campo.

Foram colocadas em cada vaso seis sementes pré-germinadas de $B$. ruziziensis. Após seis dias, foi feito desbaste da forrageira para quatro plantas por unidade experimental, que se desenvolveram por 31 dias, formando em média $70 \mathrm{~g}$ de matéria verde (aproximadamente $3.500 \mathrm{~kg} \mathrm{ha}^{-1}$ de matéria seca) por rizotron. Em cinco dos dez rizotrons onde foi semeada a forrageira, retirou-se a parte aérea, transferindo-as para outros cinco rizotrons, caracterizando assim os tratamentos com raiz e com parte aérea. Em seguida, foram colocadas seis sementes de algodão (cultivar de FMT 701) por rizotron, a $1,0 \mathrm{~cm}$ de profundidade, e a emergência se deu quatro dias depois. Por ocasião da semeadura do algodão, foi fixado um filme de plástico transparente na parede de vidro dos rizotrons, para fazer as marcações e o acompanhamento do crescimento das raízes. Após a emergência, procedeu-se ao desbaste para a condução de duas plantas por unidade experimental. Não foi realizado nenhum tipo de tratamento de sementes.

Um dia após a emergência (DAE), iniciouse a avaliação do crescimento do sistema radicular por meio de marcações, com canetas coloridas, no filme plástico das raízes que cresceram junto ao vidro. As avaliações repetiram-se em intervalos de três dias, até o
13 DAE. A última avaliação ocorreu no 15o DAE, totalizando seis avaliações.

Após esse período, as plantas foram cortadas na altura do colo, postas em estufa de circulação forçada de ar a $60{ }^{\circ} \mathrm{C}$ para obtenção da matéria seca e, posteriormente, moídas para determinação dos teores de N, P e K (Malavolta et al., 1997) e cálculo do acúmulo desses nutrientes nas plantas. A eficiência de absorção de N, P e K foi calculada dividindose a quantidade de nutrientes acumulada pela planta pelo comprimento das raízes.

Os filmes plásticos, com as anotações de crescimento radicular do algodão ao longo dos 15 dias, foram avaliados seguindo metodologia proposta por Tennant (1975), determinandose assim o comprimento radicular (L). Em resumo, os filmes foram colocados sobre uma folha marcada com quadrículos de $0,5 \mathrm{~cm}$ de lado e foram contadas as interseções das raízes com as linhas. O comprimento radicular foi calculado como: $\mathrm{L}=\mathrm{N} \times 14 / 16$, em que: $\mathrm{L}$ comprimento radicular; e N - número de interseções.

O delineamento experimental utilizado foi em blocos casualizados, com quatro tratamentos e cinco repetições. Os dados obtidos foram submetidos à análise de variância, e as médias dos tratamentos que apresentaram significância no teste $\mathrm{F}$ foram comparadas pelo teste $\mathrm{t}(\mathrm{DMS}, \mathrm{P} \leq 0,05)$. Para comprimento radicular e altura de planta, foi realizada análise de regressão, considerando-se como fator quantitativo as datas de avaliação. A partir da derivada primeira das equações de comprimento radicular e da parte aérea do algodão, obteve-se a taxa de crescimento radicular e da parte aérea.

\section{RESULTADOS E DISCUSSÃO}

A presença de raízes de braquiária prejudicou a produção de matéria seca da parte aérea do algodoeiro (Tabela 1). Em trabalho desenvolvido com a soja, Olibone et al. (2006) verificaram que, embora a palha de sorgo-deguiné tenha prejudicado o crescimento, a matéria seca da parte aérea foi maior quando a leguminosa foi cultivada na presença somente das raízes de sorgo-de-guiné. Assim, a soja, apesar do efeito alelopático da palha, não 
Tabela 1 - Matéria seca (MS) da parte aérea e taxa de crescimento da parte aérea (TCPA) do algodoeiro na presença e ausência de raiz e parte aérea de $B$. ruziziensis

\begin{tabular}{|l|c|c|}
\hline \multicolumn{1}{|c|}{ Tratamento } & $\begin{array}{c}\text { MS da parte } \\
\text { aérea } \\
\text { (g por planta) }\end{array}$ & $\begin{array}{c}\text { TCPA } \\
\left(\mathrm{cm} \mathrm{dia}^{-1}\right)\end{array}$ \\
\hline Planta inteira & 0,38 & 0,60 \\
\hline Raiz & 0,33 & 0,59 \\
\hline Parte aérea & 0,41 & 0,62 \\
\hline Testemunha & 0,44 & 0,67 \\
\hline Média & 0,39 & 0,62 \\
\hline LSD $(0,05)$ & 0,08 & - \\
\hline
\end{tabular}

$\mathrm{CV}(\%): 15,53$.

sofreu competição pelo nitrato, uma vez que a produção de massa seca não foi afetada na presença de raízes, ao contrário do que foi observado no presente trabalho. Uma provável explicação para a diferença nos resultados seria que a soja, por fixar o $\mathrm{N}$ do ar, não dependeria tanto do $\mathrm{N}$ do solo.

A altura final do algodoeiro, aos $15 \mathrm{DAE}$, foi diminuída na presença de raízes de braquiária no solo (Figura 1). Esse efeito relaciona- se ao menor crescimento radicular que também foi observado na presença das raízes de braquiária (Figura 2), pois, conforme resultados de Mian et al. (1993), existe forte correlação entre o crescimento das raízes e o da parte aérea das plantas.

A maior altura observada nos tratamentos com palha na superficie poderia ser devido ao estiolamento inicial da planta para ultrapassar a camada de palha depositada na superficie do solo, como discutido por Maciel et al. (2003), porém esse efeito pode ser descartado neste trabalho, pois os tratamentos sem palhada tiveram a superficie do solo coberta com espuma. Embora resultados obtidos por Bloodworth \& Johnson (1995) e Pettigrew et al. (2009) indiquem que a altura final da planta do algodoeiro não é afetada pelo sistema de cultivo, seja ele com a presença de culturas de cobertura, sistema convencional ou cultivo minimo, observou-se que no presente trabalho houve efeito na altura inicial da planta.

Menores taxas de crescimento da parte aérea do algodoeiro foram observadas nos tratamentos que continham raiz de braquiária (Tabela 1). A presença de raízes de plantas de cobertura forma bioporos que podem facilitar o crescimento da cultura subsequente (Silva \& Rosolem, 2001; Olibone et al., 2006) - efeito contrário ao observado no presente trabalho. Esse efeito negativo pode estar relacionado à competição por nutrientes, visto que as raízes de braquiária podem ter imobilizado nutrientes do solo, reduzindo assim sua disponibilidade para o algodoeiro. Evidenciando esse fato, observou-se menor absorção de $\mathrm{N}$ nos tratamentos que continham raizes da forrageira (Figura 4). Além disso, Jawson \& Elliott (1986) relataram que a decomposição e liberação de compostos das raízes das plantas são mais lentas que as da parte aérea, devido à menor biomassa microbiana presente nas raízes.

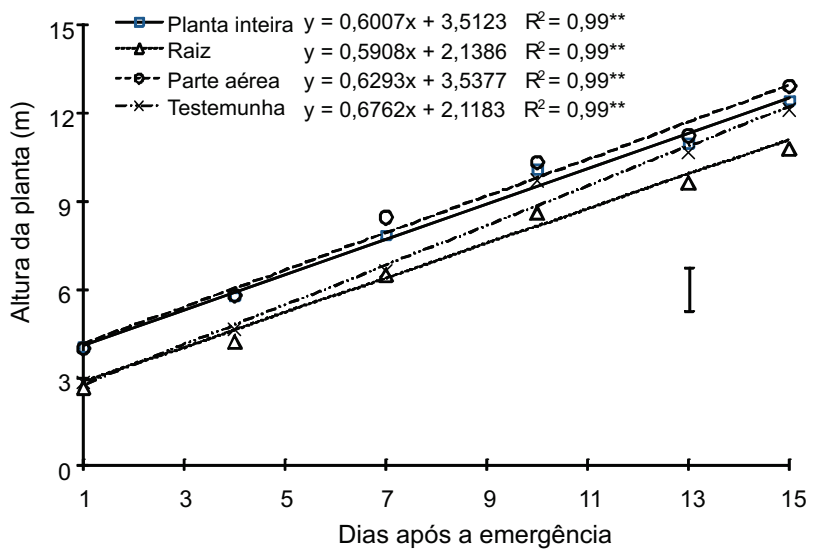

Figura 1 - Altura da planta de algodão cultivado na presença e ausência de raiz e de parte aérea de Brachiaria ruziziensis. A barra vertical representa a diferença mínima significativa.

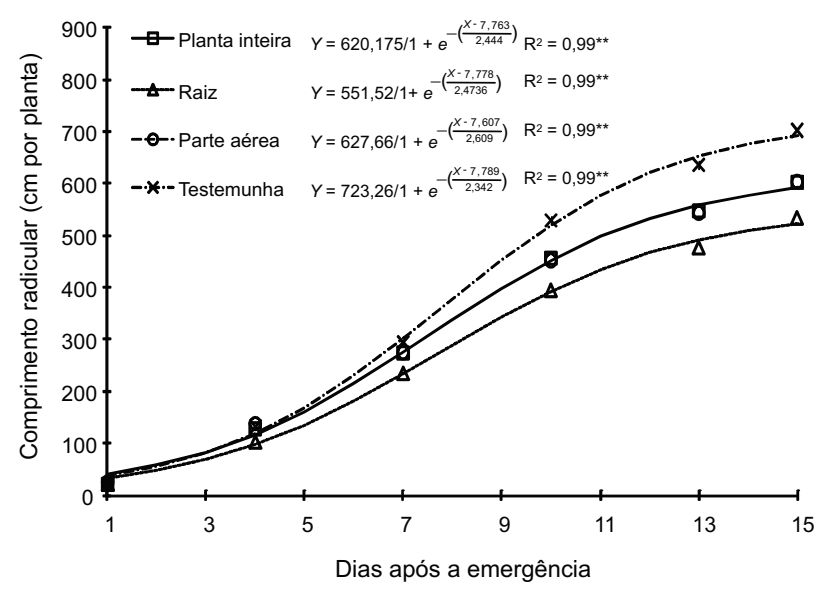

Figura 2 - Crescimento radicular do algodoeiro cultivado na presença e ausência de raiz e de parte aérea de Brachiaria ruziziensis. 
Como a raiz do algodoeiro cresceu entre as raízes da braquiária, esse efeito de deficiência de $\mathrm{N}$ pela imobilização foi mais evidente, pelo menos no início do desenvolvimento da planta de algodão, evidenciando que a cultura necessita de outras fontes de $\mathrm{N}$ para seu adequado desenvolvimento.

O menor crescimento radicular do algodoeiro foi observado quando este foi cultivado sobre resíduos de raiz de braquiária, e esse efeito foi mais expressivo a partir do sétimo dia da emergência (Figura 2), demonstrando assim novamente o efeito negativo da raiz de braquiária no desenvolvimento inicial do algodoeiro. Reichert et al. (2009), em trabalho com feijão, observaram que o crescimento radicular foi pouco afetado pelo sistema de cultivo (sistema de plantio direto com cobertura de aveia-preta, sistema convencional ou escarificação), mas os autores verificaram maior quantidade de raízes secundárias do feijoeiro quando este foi cultivado no sistema convencional ou no solo escarificado. Neste mesmo trabalho, os autores não isolaram a raiz e a parte aérea da planta de cobertura, o que não permite atribuir o efeito a nenhuma das partes da planta sobre o crescimento radicular do feijoeiro. Já no presente trabalho, com a partição da planta em raiz e parte aérea, fica claro que o efeito deletério é causado pelas raízes de braquiária, pois, quando o algodoeiro foi cultivado sobre a parte aérea ou sobre a planta inteira da braquiária, o efeito negativo sobre o crescimento foi minimizado. Também Bauer \& Reeves (1999) observaram menor crescimento radicular do algodoeiro cultivado sob resíduos de aveia-preta em relação ao que foi cultivado em solo sem cobertura, pois houve diminuição da elongação das raízes do algodoeiro. Apesar de os autores não citarem o motivo da diminuição do crescimento radicular, acredita-se que, além de um possivel efeito alelopático, possa haver competição por $\mathrm{N}$ - fato esse observado no presente trabalho.

Analisando as Figuras 1 e 2, observa-se que o menor crescimento radicular do algodoeiro provocado pela raiz de braquiária acarretou menor crescimento da parte aérea do algodoeiro. Resultados similares foram ralatados por Mian et al. (1993), em que o crescimento radicular vigoroso resultou em crescimento vigoroso da parte aérea do trigo, por Girdthai et al. (2010), em amendoim, e por Kennedy \& Hutchinson (1999), em algodão. Isso leva a crer que a cultura tende a manter equilíbrio na sua relação raiz/parte aérea; a ocorrência de prejuízos em um dos fatores será acompanhada de redução do outro fator.

A taxa de crescimento radicular apresentou valor máximo entre o sétimo e o oitavo dia após a emergência em todos os tratamentos, e foi menor onde havia raízes de braquiária (Figura 3), fato que pode estar relacionado à já citada imobilização de $\mathrm{N}$ pelas raízes da forrageira. Acredita-se ainda que a parte aérea da forrageira, devido ao seu maior potencial de liberação de nutrientes, possa minimizar os efeitos da imobilização das raízes. O efeito dos tratamentos pôde ser visualizado até os 10-12 dias após a emergência; na última avaliação, as curvas praticamente se igualaram. Resultados semelhantes foram observados por Souza et al. (2007), em que a maior taxa de crescimento radicular do algodoeiro foi obtida entre o 12 o e o 15 o dia da semeadura ( $9 \circ$ a $12^{\circ}$ dia da emergência), para todos os seus tratamentos. Também o efeito dos tratamentos no presente trabalho nas últimas avaliações pode ter sido anulado devido à restrição imposta pela área do rizotron, conforme observado por Arp (1991).

$\mathrm{O}$ teor e o acúmulo de $\mathrm{N}$ na parte aérea do algodão foram menores nas plantas que foram cultivadas sobre resíduos de raiz de braquiária (raiz e planta inteira) (Figuras 4 e 5). Quanto mais altos forem os conteúdos de lignina e a relação $\mathrm{C} / \mathrm{N}$ do resíduo vegetal, mais lenta será a sua decomposição (Floss, 2000). Por outro lado, as fases do ciclo do nitrogênio são afetadas pela alelopatia, modificando as relações entre o nitrogênio livre, a fixação de nitrogênio e a adição de matéria orgânica (Rice, 1984); isso foi comprovado em pesquisas que relatam a interferência da alelopatia na dinâmica do nitrogênio no solo (Stiven, 1952; Mills, 1953; Meiklejohn, 1962).

Também, o teor de $\mathrm{N}$ no sistema altera a velocidade de decomposição, pois os microrganismos imobilizam o $\mathrm{N}$ do solo para a mineralização do material orgânico, sendo o consumo de $\mathrm{N}$ maior quanto maior for a relação $\mathrm{C} / \mathrm{N}$ do resíduo (Kliemann et al., 2006). Como a braquiária apresenta alta 


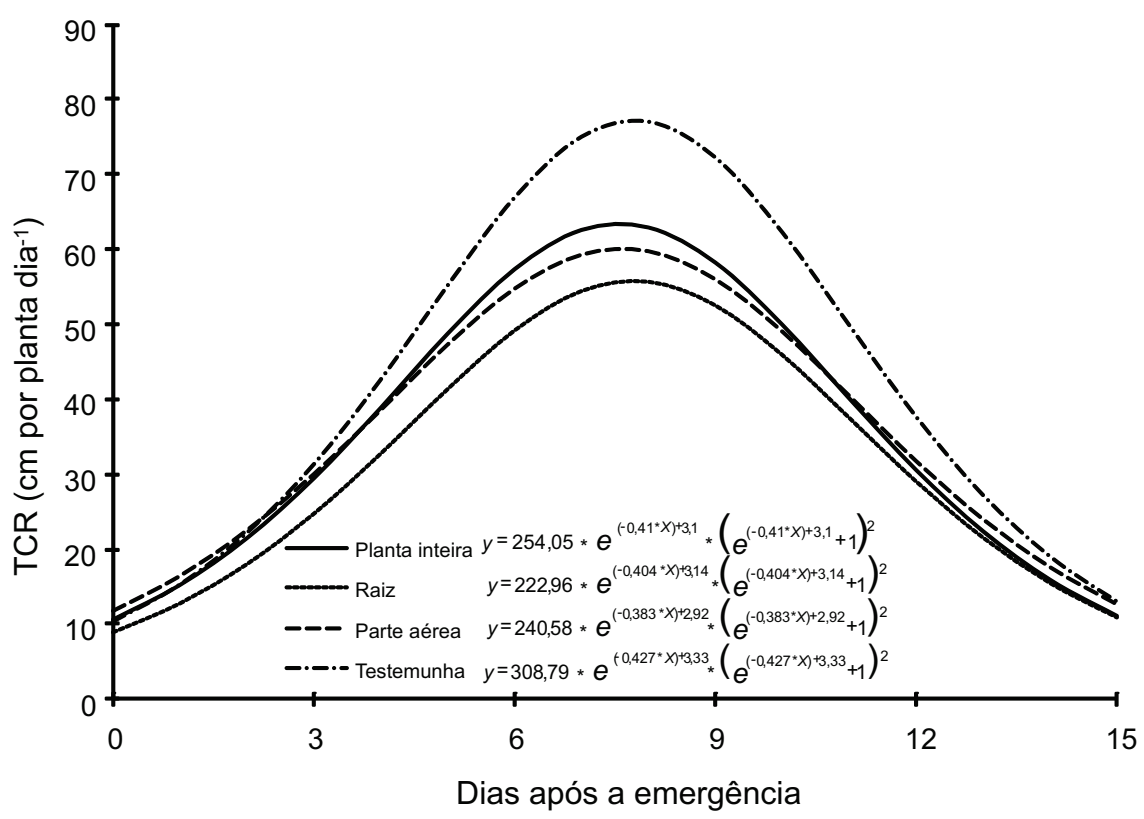

Figura 3 - Taxa de crescimento radicular (TCR) do algodoeiro cultivado na presença e ausência de raiz e de parte aérea de Brachiaria ruziziensis.

relação $\mathrm{C} / \mathrm{N}$, o consumo de $\mathrm{N}$ para sua mineralização também é maior. Isso explica o menor teor e acúmulo desse nutriente nas plantas dos tratamentos com presença de restos de braquiária, em comparação à testemunha, pois nesse caso o $\mathrm{N}$ aplicado via fertilizante na adubação de base pôde ser integralmente utilizado para o crescimento do algodoeiro.

Resultados semelhantes aos deste trabalho também foram observados por Vargas et al. (2005) em plantas de milho, em que o sistema convencional (sem residuos de palha e de raiz) proporcionou maior acúmulo de $\mathrm{N}$ na parte aérea de milho que o sistema com semeadura direta sobre palhada de aveia-preta, que apresentou relação $\mathrm{C} / \mathrm{N}$ de 59 no momento do manejo. Uma evidência da interação alelopatia e nitrogênio foi encontrada por Souza et al. (1997), cuja incorporação de $B$. decumbens no solo reduziu significativamente a quantidade de nitrogênio na solução do solo.

Por sua vez, o teor de P na parte aérea do algodoeiro foi maior nos tratamentos que tinham raizes de braquiária (raiz e planta inteira) (Figura 4), apesar de o acúmulo de $\mathrm{P}$ na parte aérea não ter sido influenciado pelos tratamentos (Figura 5). Esse fato pode estar relacionado à capacidade das raízes de
B. ruziziensis de solubilizar frações de $\mathrm{P}$ não disponiveis para outras culturas (Merlin et al., 2009), tornando esse elemento disponível, seja pela ação de exsudatos radiculares, seja pela posterior decomposição da parte aérea da forrageira.

O teor e o acúmulo de K na parte aérea do algodoeiro aumentaram onde havia a parte aérea de braquiária, independentemente da presença de raiz (Figuras 4 e 5). Os resíduos da parte aérea foram provenientes do tratamento com raiz, e as plantas de algodão deste tratamento foram as que menos acumularam $\mathrm{K}$ (Figura 5). O maior teor e acúmulo de $\mathrm{K}$ na parte aérea do algodoeiro se deu pela lavagem do $\mathrm{K}$ no tecido vegetal da parte aérea da forrageira, em decorrência da ação da reposição de água nos rizotrons. Por ser o $\mathrm{K}$ altamente móvel no floema, formando ligações com complexos orgânicos de fácil reversibilidade, sua liberação do tecido vegetal é muito rápida, tornando-o disponivel para culturas subsequentes (Rosolem et al., 2003; Calonego et al., 2005; Boer et al., 2007; Garcia et al., 2008). De acordo com Boer et al. (2007), o potássio é o nutriente acumulado e liberado em maior quantidade em gramíneas utilizadas como plantas de cobertura. Em razão disso, pode-se considerar um aproveitamento de $100 \%$ do 


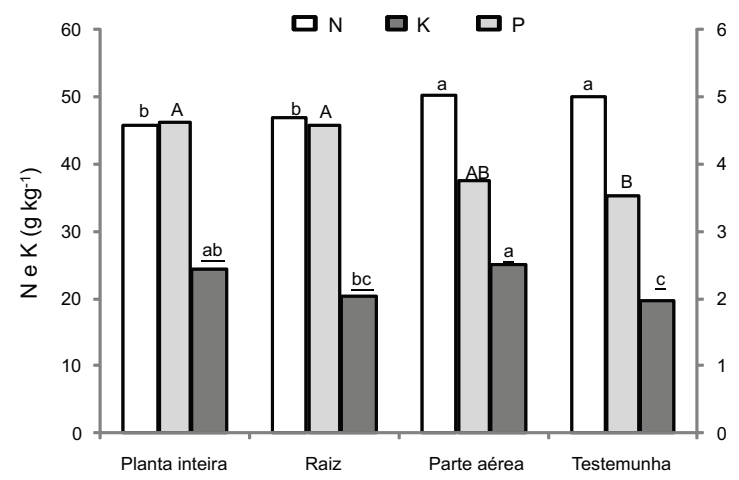

Figura 4 - Teor de N, P e K na parte aérea do algodoeiro cultivado na presença e ausência de raiz e de parte aérea de Brachiaria ruziziensis. a $>\mathrm{b}$ para o $\mathrm{N}, \mathrm{A}>\mathrm{B}$ para o $\mathrm{P}$ e $\underline{\mathrm{a}}>\underline{\mathrm{b}}$ para o $\mathrm{K}$, pelo teste $\mathrm{t}$ (LSD) a $5 \%$.

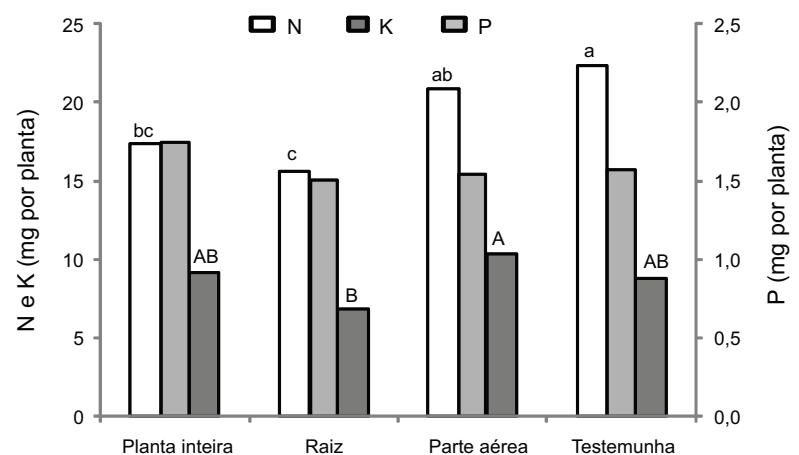

Figura 5 - Acúmulo de N, P e K na parte aérea do algodoeiro cultivado na presença e ausência de raiz e de parte aérea de Brachiaria ruziziensis. a $>\mathrm{b}$ para o $\mathrm{N}$ e $\mathrm{A}>\mathrm{B}$ para o $\mathrm{K}$, pelo teste $\mathrm{t}(\mathrm{LSD})$ a $5 \%$.

potássio proveniente dos restos culturais, porém há de se considerarem também as perdas desse nutriente por lixiviação (Spain \& Salinas, 1985).

A presença de raízes de $B$. ruziziensis resulta em menor crescimento inicial da parte aérea e do sistema radicular do algodoeiro, bem como em menor absorção de $\mathrm{N}$ pela planta, mas provoca maior absorção de fósforo do solo. A presença de resíduos da parte aérea da braquiária na superfície do solo proporciona maior teor e acúmulo de $\mathrm{K}$ pelo algodoeiro. $\mathrm{O}$ menor desenvolvimento do algodoeiro, cultivado após a forrageira, está relacionado à imobilização de $\mathrm{N}$ pelas raízes de $B$. ruziziensis, sugerindo que mais estudos devem ser desenvolvidos sobre a dose e o parcelamento da adubação nitrogenada para a cultura do algodão cultivado após essa gramínea.

\section{LITERATURA CITADA}

ARP, W. Effects of source-sink relations on photosynthetic acclimation to elevated $\mathrm{CO}_{2}$. Plant Cell Environ., v. 14, n. 8, p. 869-875, 1991.

BAUER, P. J.; REEVES. D. W. A comparison of winter cereal species and planting dates as residue cover for cotton grown with conservation tillage. Crop Sci., v. 39, n. 6 , p. 1824-1830, 1999.

BLOODWORTH, L. H.; JOHNSON, J. R. Cover crops and tillage effects on cotton. J. Produc. Agric., v. 8, n. 1, p. 106-112, 1995.

BOER, C. A. et al. Ciclagem de nutrientes por plantas de cobertura na entressafra em um solo de cerrado. Pesq. Agropec. Bras., v. 42, n. 9, p. 1269-1276, 2007.

CAloneGO, J. C.; FOLONI, J. S. S.; ROSOLEM, C. A. Lixiviação de potássio da palha de plantas de cobertura em diferentes estádios de senescência após a dessecação química. R. Bras. Ci. Solo, v. 29, n. 1, p. 99-108, 2005.

COOK, H. F.; VALDES, G. S. B.; LEE, H. C. Mulch effects on rainfall interception, soil physical characteristics and temperature under Zea mays L. Soil Tillage Res., v. 91, n. 1-2, p. 227-235, 2006.

EMPRESA BRASILEIRA DE PESQUISA AGROPECUÁRIA - EMBRAPA. Centro Nacional de Pesquisa de Solos. Sistema brasileiro de classificação dos solos. Rio de Janeiro: Embrapa-SPI/Embrapa-CNPS, 1999. $412 \mathrm{p}$.

FLOSS, E. Benefícios da biomassa de aveia ao sistema de semeadura direta. R. Plantio Direto, n. 57, p. 25-29, 2000.

FOLONI, J. S. S.; ROSOLEM, C. A. Potassium balance in soybean grown under no-till. In: INTERNATIONAL CROP SCIENCE CONGRESS, 4., 2004. Brisbane. Proceedings... Brisbane: ICSS, 2004. Disponível em: $<$ http:// www.cropscience.org.au/icsc2004/poster/2/5/5/ 907_rosolemca.htm>. Acesso em: 15 mar. 2010.

GARCIA, R. A. et al. Potassium cycling in a corn-brachiaria cropping system. Europ. J. Agron., v. 28, n. 4, p. 579-585, 2008.

GIRDTHAI, T. et al. Relationship between root characteristics of peanut in hydroponics and pot studies. Crop Sci., v. 50, n. 1, p. 159-167, 2010.

JAWSON, M. D.; ELLIOTT, L. F. Carbon and nitrogen transformations during wheat straw and root decomposition. Soil Biol. Biochem., v. 18, n. 1, p. 15-22, 1986.

KENNEDY, C.; HUTCHINSON, B. Cotton root and shoot growth under different tillage systems In: BELTWIDE COTTON CONFERENCE, 1999, Orlando. Proceedings... Orlando: 1999.

Planta Daninha, Viçosa-MG, v. 30, n. 4, p. 783-790, 2012 
KLIEMANN, H. J.; BRAZ, A. J. P. B.; SILVEIRA, P. M. Taxas de decomposição de resíduos de espécies de cobertura em latossolo vermelho distroférrico. Pesq. Agropec. Trop., v. 36, n. 1, p. 21-28, 2006.

KLUTHCOUSKI, J.; AIDAR, H. Implantação, condução e resultados obtidos com o sistema Santa Fé. In: KLUTHCOUSKI, J.; STONE, L. F.; AIDAR, H. (Ed.). Integração lavoura - pecuária. Santo Antônio de Goiás: Embrapa Arroz e Feijão. 2003. p. 407-441.

MACIEL, C. D. G. et al. Influência do manejo da palhada de capim-braquiária (Brachiaria decumbens) sobre o desenvolvimento inicial de soja (Glycine max) e amendoimbravo (Euphorbia heterophylla). Planta Daninha, v. 21, n. 3, p. 365-373, 2003.

MALAVOLTA, E.; VITTI, G. C.; OLIVEIRA, S. A. Avaliação do estado nutricional das plantas: princípios e aplicações. 2.ed. Piracicaba: Potafos, 1997. 319 p.

MARY, B. et al. Interactions between decomposition of plant residues and nitrogen cycling in soil. Plant Soil, v. 181, n. 1, p. 71-82, 1996.

MEIKLEJOHN, J. Microbiology of the nitrogen cycle in some Ghana soils. Emp. J. Exper. Agric., v. 30, n. 1, p. 115-126, 1962.

MERLIN, A.; ROSOLEM, C. A.; BÜLL, J. C. L. Soil phosphorus forms after brachiaria. In: INTERNATIONAL PLANT NUTRITION COLLOQUIUM, 16., 2009, Davis. Proceedings... Davis: UC, 2009. Disponível em: <http:// escholarship.org/uc/item/6rf8j1tz>. Acesso em: 15 mar. 2010.

MIAN, M. A. R. et al. Root growth of wheat genotypes in hydroponic culture and in the greenhouse under different soil moisture regimes. Crop Sci., v. 33, n. 2, p. 283-286, 1993.

MILLS, W. R. Nitrate accumulation in Uganda soils. East African Agric. J., v. 19, n. 1, p. 53-54, 1953.

OLIBONE, D. et al. Crescimento inicial da soja sob efeito de resíduos de sorgo. Planta Daninha, v. 24, n. 2, p. 255-261, 2006.

PERIN, A. et al. Sunnhemp and millet as green manure for tropical maize production. Sci. Agric., v. 63, n. 5, p. 453-459, 2006.

PETTIGREW, W. T. et al. Impact of varying planting dates and tillage systems on cotton growth and lint yield production. Agron. J., v. 101, n. 5, p. 1131-1139, 2009.

PRANDO, M. B. et al. Infiltração de água no solo em função da escarificação e rotação de culturas. R. Bras. Ci. Solo, v. 34, n. 3, p. 693-700, 2010.

RAIJ, B.van et al. (Ed.). Análise química para avaliação da fertilidade de solos tropicais. Campinas: Instituto Agronômico de Campinas, 2001. 285 p.

Planta Daninha, Viçosa-MG, v. 30, n. 4, p. 783-790, 2012
REICHERT, J. M. et al. Variação temporal de propriedades físicas do solo e crescimento radicular de feijoeiro em quatro sistemas de manejo. Pesq. Agropec. Bras., v. 44, n. 3, p. 310-319, 2009.

ROSOLEM, C. A.; CALONEGO, J. C.; FOLONI, J. S. S. Lixiviação de potássio da palha de espécies de cobertura do solo de acordo com a quantidade de chuva aplicada. R. Bras. Ci. Solo, v. 27, n. 2, p. 355-362, 2003.

ROSOLEM, C. A. et al. Lixiviação de potássio no solo de acordo com suas doses aplicadas sobre palha de milheto. R. Bras. Ci. Solo, v. 30, n. 5, p. 813-819, 2006.

SILVA, R. H.; ROSOLEM, C. A. Influência da cultura anterior e da compactação do solo na absorção de macronutrientes em soja. Pesq. Agropec. Bras., v. 36, n. 10, p. 1269-1275, 2001.

HIRATA, A. C. et al. Plantas de cobertura no controle de plantas daninhas na cultura do tomate em plantio direto. Planta Daninha, v. 27, n. 3, p. 465-472, 2009.

RICE, E. L. Allelopathy. 2. ed. Orlando: Academic, 1984. $422 \mathrm{p}$.

SPAIN, J. M.; SALINAS, J. G. A reciclagem de nutrientes nas pastagens tropicais. In: REUNIÃO BRASILEIRA DE FERTILIDADE DO SOLO, Ilhéus, 1985. Anais... Ilhéus: 1985. p. 159-299.

SOUZA, F. S.; FARINELLI, R.; ROSOLEM, C. A. Desenvolvimento radicular do algodoeiro em resposta à localização do fertilizante. R. Bras. Ci. Solo, v. 31, n. 2, p. 387-392, 2007.

SOUZA, L. S. et al. Efeito alelopático de capim-braquiária (Brachiaria decumbens) sobre o crescimento inicial de sete espécies de plantas cultivadas. Planta Daninha, v. 24, n. 4, p. $657-668,2006$.

SOUZA FILHO, A. P. S.; MOURÃO JR., M. Padrão de resposta de Mimosa pudica e Senna obtusifolia à atividade potencialmente alelopática de espécies de

Poaceae. Planta Daninha, v. 28, p. 927-938, 2010. (Numero Especial)

SOUZA, L. S. et al. Possíveis efeitos alelopáticos de Brachiaria decumbens Stapf. sobre o desenvolvimento inicial de limão cravo (Citrus limonia Osbeck). Planta Daninha, v. 15, n. 2, p. 122-129, 1997.

STIVEN, G. Production of antibiotic substances by roots of a grass [Trachypogon plumosus (H.B.K.) Nees] and Pentanisia variabilis (E. Mey.) Hary. (Rubiaceae). Nature, v. 170, p. 712-713, 1952.

TENNANT, D. A. A test of a modified line intersect method of estimating root length. J. Ecol., v. 63, n. 3, p. 995-1001, 1975.

VARGAS, L. K.; SELBACH, P. A.; SA, E. L. S. Imobilização de nitrogênio em solo cultivado com milho em sucessão à aveia preta nos sistemas plantio direto e convencional. Ci. Rural, v. 35, n. 1, p. 76-83, 2005. 